\title{
Agricultural Subsidies, Production Certification and Green Pesticide Use Rate: Evidence from Experiments
}

Lin Nan ${ }^{1}$ Zhang Yang ${ }^{1} \mathrm{Hu} \mathrm{Xin}^{1}$ Liu Lijuan ${ }^{1}$, Chengliang ${ }^{1}$ *

${ }^{1}$ School of Economics and Management, Beijing Forestry University, Beijing 100083, China;

linnan@bjfu.edu.com(N.L.); Zhangyang06012@aliyun.com(Y.Z.); fadahuxin@163.com(X.H); liulijuanx@126.com(L.L.).

*Correspondence:wubjfu@163.com 


\section{Agricultural Subsidies, Production Certification and Green Pesticide Use Rate: Evidence from Experiments}

Abstract: This paper studies the impact of agricultural subsidies and product certification ${ }^{1}$ on the use rate of green pesticides based on experimental economics. We found that agricultural subsidies effectively increased the utilization rate of green pesticides. If the agricultural subsidies raised from $20 \%$ to $100 \%$, the green pesticides' using rate increased by $438.51 \%$. We also found that product certification increased the utilization rate of green pesticides by $376.16 \% \%$.The increase of agricultural subsidies is more effective than the product certification. Under a higher proportion of agricultural subsidies, farmers' behavior will maintain "status bias". Therefore, there are three suggestions proposed. Firstly, because of high price of green pesticides and lower production, the subsidies for agricultural materials should raise greatly to effectively improve the utilization rate of green pesticides. It is recommended that green pesticide provided free of charge in some wealthy areas. Secondly, both subsidies and product certification can improve the use rate of green pesticides. However, since the effect of agricultural subsidies is better than product certification, and farmers may have status bias. Therefore, it is recommended to give priority to the substantial increase on the proportion of agricultural subsidies, and then to product certification.

Key Words: Green pesticides; Agricultural subsidies; Product certification; Laboratory experiment

\section{Introduction}

Featured by low toxicity, low residue and environmentally friendly properties, green pesticides are ace substitutes for non-green pesticides. Although there are relevant policies released by the government departments to guide farmers to purchase and use green pesticides, the use rate of green pesticides by farmers in realistic production is still not high (Yang X, Lin Q Y, 2011; Jiang L N, Zhao X, 2017). Farmer are the main provider of primary products, and its safety of production behavior is severely important. Influencing factors of farmers' green pesticide selection behavior has also been a research hotspot in the academic circle. Improving the use rate of green pesticides on farmers has exerted great effects reducing agricultural non-point source pollution and ensuring the quality and safety of agricultural products. Considering that there is no significant difference in the using method of green and non-green pesticides, this paper will focus on how to improve the use rate of green pesticides by farmers from an economic perspective.

\footnotetext{
${ }^{1}$ China's agricultural product certification system includes three categories: pollution-free agricultural products, green agricultural products, organic agricultural products. The product certification in this article refers specifically to pollution-free product certification.
} 
As the main responsibility of primary production, farmer is the original factor that influences primary products' quality. Therefore, the research on farmers' behavior has always been a hot topic of scholars at home and abroad. Subsidies and pesticide residue examination of agricultural products were essential factors affecting farmers' selection of safe pesticides (Wu L H, Hou B, Gao S R, 2011; Schreinemachers P, Tipraqsa P, 2012). Pesticide information was also very important for farmers to choose green pesticides. If information was asymmetric, farmers may think that using green pesticides cannot increase income and has greater risks (Ervin, David E, 1982). Wang H S (2004) suggested that when market development was not perfect, information asymmetry was the reason why farmers often over-use fertilizers and pesticides to ensure high yield. The government's agricultural technology training for farmers was an important channel for farmers to obtain the information about green pesticide and learn to take this technology into full use. Under the guidance of agricultural technicians, farmers not only can understand and master green pesticide information and knowledge to a substantial extent, but also the benefits of using green pesticides. Therefore, agricultural technical training could encourage farmers to use green pesticides (Goodhue R, Klonsky K, Mohapatra S, 2010; Ervin, David E, 1982; Nowak P J, 1987; Greene, W H, 2003). Additionally, the tips on the labels of pesticide bottle and the pesticide poisoning experience of farmers also affected farmers' pesticide selection behavior (Khan M, 2009).

Pollution-free certification, green certification and organic certification are included in China's primary product certification system. Among them, non-polluting certification is the fundamental level, the products which are not certified will be classified as ordinary agricultural products. Ren Z and Xue X L (2016)pointed that farmers were more willing to use non-polluted pesticides only when the income was significantly higher than that of pollution-free pesticides. Li G W et al. (2006) examined the impact of pollution-free agricultural product certification on farmers' production efficiency and the utilization of pesticides and fertilizer, showing that the production efficiency of pollution-free agricultural products was significant, while the pesticide usage was not significantly different from that of ordinary agricultural products. However, most domestic scholars believe that the individual and family characteristics of farmers significantly influenced their pesticide use behavior (Wang Z G et al, 2012; Zhu D, et al., 2014).

Since the data of income, cost and other information usually recorded in booklet, while 
the production behavior data was often vague and untraceable and the questionnaire was difficult to gain farmers' behavior data. In the absence of natural behavioral data, relevant behavioral data obtained in the simulation of realistic production scenarios with experimental economic research methods (Suter and Vossler, 2013). Therefore, the experimental economics research method (Falk and Heckman, 2009), which is a major source of knowledge in the social sciences, has gradually introduced into policy design and evaluation in recent years.

In the field of agriculture, foreign scholars have done extensive experiments on agricultural non-point source pollution. Spraggon (2002) was the first to introduce the experimental research on non-point source pollution controlling policies based on collective performance, in whose study four exogenous policy instruments were tested, included tax/subsidy, tax, subsidy and collective fines. Since then, a numbers of scholars in this field have emerged, such as Cason, Suter, Poe, Vossler and so on, who used laboratory experiments frequently to conduct researches. In contrast, China's policy research on non-point source pollution controlling was very scarce, and relevant experimental research results have not been officially published. By combing the literature, we found that foreign research mainly focuses on two aspects, the first one was the experimental test of various collective incentive tools, which occupied a large proportion, and the second was the experimental evaluation of the auction mechanism. Farmer mainly relied on group performance (Segerson, 1988; Xepapadeas, 1991; Horan et al., 1998; Horan et al., 2002; Alpizar F et al., 2004; Suter J F. et al., 2010 ), including ambient tax, ambient subsidy, collective fines, voluntary-threat approaches, and informal mechanisms, such as peer punishment. While the latter mainly concerned motivates individuals (Cason, 2004; Cason, 2005; Ferraro, 2008; Glebe, 2013).

Wang X M et al. (2015), Zhao J J et al. (2017), Shen Y Q et al. (2016) and Bai J D et al. (2016) all used experimental economics methods, quantified the risk characteristics of farmers by MPL method. Ying R Y and Zhu Y (2015) employed participatory research methods and experimental economics methods to analyze the impact of agricultural technology training methods on farmers' chemical input behaviors and their mechanisms through designing different agricultural technology training field experiments. Chen Y S and others carried out a series of laboratory experiments to analyze farmers' choice of environmentally friendly agricultural materials (Chen Y S, et al., 2016) and food safety traceability information 
transmission behavior (Liang J, et al., 2015).

From the perspective of research content, the existing researches mainly focused on the impact of subsidies, product certification, information factors, and farmers' characteristics on farmers' pesticide selection behavior. According to research methods, foreign scholars have more fruitful research results on experimental economics, yet domestic scholars have very few experimental studies in agriculture. Most domestic scholars got the data of farmer behavior research based on questionnaires, which means "statically" study the impact of certain factors or multiple factors on the usage of green pesticides by farmers, but farmers will experience a series of processes before using green pesticides finally, that is subjective cognition, normperceived behavioral control, behavioral intention and taking intention. Farmers' behavior affected by both subjective and objective factors, and repeated iterations are inevitable before their final decisions. While questionnaires and statistics usually used in research are impossible to reveal the "complex" and "repetitive" dynamic process of farmers' decision making, which cannot reflect the above dynamic process and is difficult to incorporate the objective and subjective factors to find the impact on farmers' green pesticide usage. The experimental economics theories and methods employed in this article can solve the above problems well. In the experimental environment, an experimental group with differentiated agricultural subsidies and product certifications constructed, which superiorly controlled the interference of unrelated variables in the research. The data of farmers' behavior process can be obtained through the "static repeat" experiment, then fully investigation of the impact of agricultural subsidies and product certification on farmers' green pesticide use rate and decision-making process can be completed.

The other parts of this paper arranged as follows. The second part put forward the theoretical hypothesis and experimental design proposed in the third part. Then the fourth part analyzes the behavioral process and results of the subjects. Meanwhile, the empirical test of the correlation between the individual characteristics of the subjects and the use rate of green pesticides conducted in the fourth part, then summarizing the experimental conclusions and recommendations in the final part. 


\section{Research hypothesis}

Driven by economic interests, farmers' decisions are productive investment choices which depend on the resources they owned and the objective environment surrounded. Economic factors also influence farmers' choice of pesticides, including the price of production materials (pesticide costs) and the realization of market value.

(1) Materials price hypothesis. As one of the basic elements of agricultural production, pesticides closely related to the production process of farmers. The price of green pesticides is much higher than that of non-green pesticides, in the future that the income of production is unpredictable, whereby farmers are more likely to choose low-cost non-green pesticides in order to reduce costs from the perspective of cost. If green pesticides get a subsidy, the initial input cost of the farmers will reduced, which compensate farmers for the "contingent loss" caused by the uncertainty in the future production. Therefore, if the appropriate price subsidy provided for farmers who apply green pesticides, it will contribute to increasing farmers' willingness to use green pesticides. Based on the above analysis, hypothesis 1 proposed.

Hypothesis 1: Agricultural subsidies can promote the use of green pesticides by farmers, and the greater the number of subsidies, the higher the use rate of green pesticides.

(2) Market value hypothesis. Primary products that used green pesticides are lower in toxicity and residue, and more likely to pass product certification. Accordingly, the market value of certified primary products is also higher. However, the realization of the market value of certified primary products is uncertain. In the case of incomplete market conditions, such as an imperfect quality inspection system for agricultural products with asymmetric information between buyers and sellers of agricultural products, it may require more transaction costs for farmers to realize the "green" addition value of their certified agricultural products. Therefore, the addition value of the certified agricultural products may not be realized, which causes the certified agricultural products amount to the general agricultural products, and the phenomenon that the bad coins expel the good money in the "lemon market" will appear. Under such circumstances, farmers are not motivated to apply green pesticides （Zhang Y H, 2004）. From the farmer's point of view, product certification is an effective means to achieve market value of the agricultural products, which may result in more product sales revenue. The agricultural 
product certification system does not require farmers to pay the certification fee, and the system is completely exogenous to the farmers. Therefore, in order to avoid the moral hazard of farmers, the experiment assumes that primary products produced by farmers will tested by professionals, and products produced that use non-green pesticides will not pass the product certification. The certification result of agricultural products is essentially a signal to release the quality of products to consumers. Consumers are willing to pay higher prices for higher quality agricultural products than ordinary agricultural products. Therefore, hypothesis 2 proposed.

Hypothesis 2: Product certification is conducive to improving the use rate of green pesticides by farmers.

\section{Material and Method}

\subsection{Research Method of Experiment Economics}

Laboratory experiments usually require abstraction and simplification, and the key to verify the effectiveness of the experiment is to extract the "typical characteristics" of the research object (Daniel H et al., 2012), that is, to maintain its essential consistency. As the main body of production, farmers usually take households as production units, and the premise of production input is to be budget-conscious and maximize income. Experimental economics based on the theory of value induction, and the experiment is mainly composed of two parts: the experimenter (the person who organizes the experiment) and the subject (the person who participated in the experiment). As long as the effective incentives given to the subjects can meet the experimental requirements, the profits obtained by the subjects in the experiment will change into cash rewards or equivalent gifts. In this laboratory experiment, 60 students from Beijing Forestry University recruited as subjects. The effective incentives for these subjects were better suited to the farmers' production expectations. At the same time, students had strong learning ability and avoided unforcedness error. The experiment used the Ztree and Zleaf software developed by the University of Zurich (Fischbacher U, 2007) to simulate different scenarios in the production of farmers. The experimenter controlled the Ztree program to conduct overall control of the experiment, and the subjects need to make decisions at the Z-leaf port. The overall operation process presented as figure 1 . 


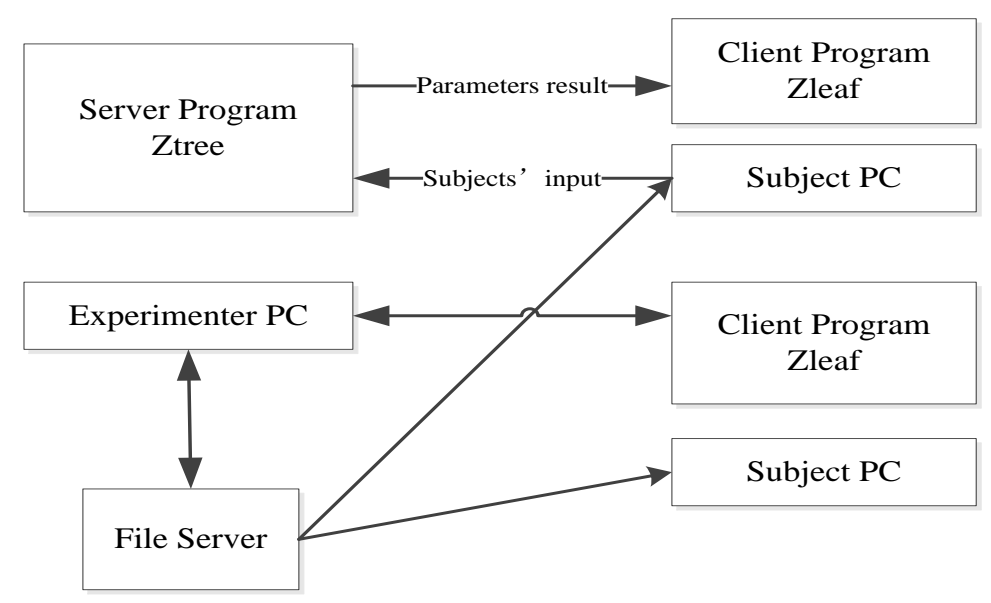

Figure 1. Client-server architecture of z-Tree

\subsection{Experimental design}

In realistic production, the price of green pesticides is about three times of non-green pesticides, and using green pesticide will generate positive externalities for ecological environment improvement, products which spraying green pesticide will also get certification to get more revenue. The experiment designed based on the above common background. In terms of agricultural subsidies, the current subsidies for pesticides are mainly purchase subsidies for green pesticide. The purchase cost of green pesticides is higher than that of nongreen pesticides, the input of farmers' own funds will reduce if subsidies provide, which can offset the cost difference between the two pesticides. Therefore, farmers may increase the use rate of green pesticides. In terms of certification, some areas have gotten pollution-free food certification as pollution-free production bases. However, most products are still belong to ordinary agricultural products. Agricultural product certification conveys product quality information to the market and consumers. Consumers are willing to pay higher prices for higher quality agricultural products than ordinary agricultural products. The product certification involved in the experiment refers only to pollution-free product certification.

The agricultural subsidies and product certifications are the basis of the experimental grouping and groups involved in this paper showed in table 1.

Table 1. Group setting of Experiment

\begin{tabular}{|c|l|l|}
\hline & \multicolumn{1}{|c|}{ Low subsidy } & \multicolumn{1}{c|}{ High subsidy } \\
\hline No certification & Control group-A & Experiment group-C \\
\hline Certification & Experiment group-B & Experiment group-D \\
\hline
\end{tabular}


Under different experimental groups, the size relationship of the unit revenue of farmers using green pesticides is $\mathrm{D}>\mathrm{B}>\mathrm{C}>\mathrm{A}$, and the unit revenue of farmers using non-green pesticides is similar among different groups, except group D, in which case the production yield of farmers using green pesticides is higher than that of using non-green pesticides.

In this experiment, 60 subjects will divide into 4 groups randomly, and each group will conduct 30 periods of experiments. The four groups constitute four experimental bureaus, and the total time of each experimental bureau is about 1 hour.

In each experimental bureau, each subject will act as vegetable producer with 10 units(mu) vegetable, these vegetables are at a high incidence of pests and diseases, thus pesticides need to be sprayed for controlling the pest. The existing pesticides can separate into two categories, namely, green pesticides and non-green pesticides, and the purchase cost as well as application effects is different. The price of green pesticides is three times that of non-green pesticides, and the effect of green pesticide application leads to an unstable yield, which means the average value is only $80 \%$ of non-green pesticide production. The specific parameter settings showed in table 2.

Table 2. Revenue formula and Parameter settings (i means different farmers, $\mathrm{j}$ means different periods)

\begin{tabular}{|c|c|c|c|}
\hline \multicolumn{4}{|c|}{ 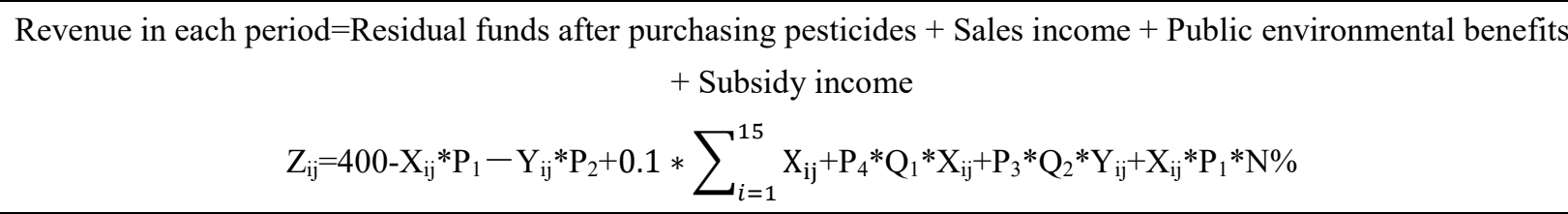 } \\
\hline $\begin{array}{c}\text { Residual funds after purchasing } \\
\text { pesticides }\end{array}$ & Sales income & $\begin{array}{l}\text { Public environmental } \\
\text { benefits }\end{array}$ & Subsidy income \\
\hline $400-\mathrm{X}_{\mathrm{ij}} * \mathrm{P}_{1}-\mathrm{Y}_{\mathrm{ij}} * \mathrm{P}_{2}$ & $\mathrm{P}_{4} * \mathrm{Q}_{1} * \mathrm{X}_{\mathrm{ij}}+\mathrm{P}_{3} * \mathrm{Q}_{2} * \mathrm{Y}_{\mathrm{ij}}$ & $0.1 * \sum_{i=1}^{15} X_{i j}$ & $\mathrm{X}_{\mathrm{ij}} * \mathrm{P}_{1} * \mathrm{~N} \%$ \\
\hline $\begin{array}{c}0 \leq X_{\mathrm{ij}} \leq 10 ; \quad 0 \leq Y_{\mathrm{ij} j} \leq 10 \\
\quad \mathrm{X}_{\mathrm{ij}}+\mathrm{Y}_{\mathrm{ij}}=10 \\
\mathrm{P} 1=30 ; \quad \mathrm{P} 2=10 ;\end{array}$ & $\begin{array}{c}\mathrm{Q} 1=240 ; \mathrm{Q} 2=300 ; \mathrm{P} 3=0.5 ; \\
\mathrm{P} 4=0.5-\mathrm{AC} \text { groups; } \\
\mathrm{P} 4=0.625-\mathrm{BD} \text { groups }\end{array}$ & All the groups & $\begin{array}{l}\mathrm{N}=20(\mathrm{AB} \text { groups }) \\
\mathrm{N}=100(\mathrm{CD} \text { groups })\end{array}$ \\
\hline $\begin{array}{l}\text { 400: initial funds in each period } \\
\text { (experimental currency) } \\
\mathrm{X}_{\mathrm{ij}}(\mathrm{mu}) \text { : green pesticide input } \\
\mathrm{Y}_{\mathrm{ij}}(\mathrm{mu}) \text { : non-green pesticide } \\
\text { input }\end{array}$ & $\begin{array}{l}\mathrm{Q}_{1}(\mathrm{~kg} / \mathrm{mu}) \text { : the yield of } \\
\text { vegetable that use green } \\
\text { pesticide; } \\
\mathrm{Q} 2(\mathrm{~kg} / \mathrm{mu}): \text { the yield of } \\
\text { vegetable that non-green }\end{array}$ & $\begin{array}{l}\text { Since the } \\
\text { environmental benefits } \\
\text { are implicit benefits } \\
\text { and cannot be realized } \\
\text { immediately, the }\end{array}$ & $\begin{array}{l}\mathrm{N} \text { : The subsidy } \\
\text { range, which is } \\
\text { arranged by the } \\
\text { price of green } \\
\text { pesticides. }\end{array}$ \\
\hline
\end{tabular}




\begin{tabular}{|c|c|c|}
\hline $\begin{array}{l}\text { P1 (yuan/mu): the price of green } \\
\text { pesticide } \\
\text { P2 (yuan/mu): the price of non- } \\
\text { green pesticide }\end{array}$ & $\begin{array}{l}\text { pesticide; } \\
\text { P3 (yuan } / \mathrm{kg}) \text { : the price of } \\
\text { vegetable without certification; } \\
\text { P4 (yuan } / \mathrm{kg} \text { ): the price of } \\
\text { vegetable price with } \\
\text { certification }\end{array}$ & $\begin{array}{l}\text { coefficient values are } \\
\text { small. }\end{array}$ \\
\hline
\end{tabular}

Note: The parameters based on the survey data of farmers in a vegetable production area in a certain city of Shandong Province, which reduce 10 times of the survey data and simplifies the actual production situation of farmers. Subjects only have various parameter information during the experiment, and the specific income formula is unknown. It will inform that the income is composed of four parts.

The basic process of the experiment follows six steps. 1) Fill in the questionnaire. Before starting the experiment, the subjects were required to complete relevant questionnaires, including the understanding of experimental economics, green pesticides, pest and disease prevention and control, and farmers' considerations of production, as well as a risk measurement table. 2) Read the experimental instructions and rules. The experimenter read instructions and rules aloud and answered the questions of the subjects. 3) Problem testing. After reading the experimental rules, the subjects entered the problem testing session. The subjects need to answer 2-3 questions about experiment constructions, they could enter the experimental session only after all the answers are correct. 4) Pre-experiment. Before starting the formal experiment, the subjects need to conduct two periods of test experiments to familiarize themselves with the specific operating environment of the experiment. 5) Formal experiment. After the test experiments, the formal experiment begins, which lasting 30 periods, and the subjects will make decisions in each period, and each period of decision-making is independent. 6) Income settlement. After the formal experiment is completed, the experimenters will distribute cash for subjects based on the pre-agreed income distribution plan. Meanwhile keeping cash distribution plan confidential is necessary during the issuance process, and the cash distribution linked to the behaviors of subjects. After each bureau of experiments, the staff ought to clean the experimental site and prepare the materials needed for the next bureau of experiments, waiting for the subjects to enter the area, repeating the steps of the previous bureau of experiments. 


\section{Experimental Results}

\subsection{Analysis of the Impact of Agricultural Subsidy on the Utilization Rate of Farmers' Green Pesticides}

In the experiment, Group A and Group $\mathrm{C}$ were the non-certified low-subsidy experimental group and the non-certified high-subsidy experimental group respectively. According to the process data of the decision-making of the participants, Table 3 and Figure 2 were finished.

Table 3. The impact of agricultural subsidies on the use rate of green pesticides

\begin{tabular}{ccccc}
\hline Group & Index & Low subsidy & High subsidy & Increase \\
& & $(20 \%)$ & $(100 \%)$ & $124.57 \%$ \\
No certification & Green pesticide use rate & $9.93 \%$ & $22.3 \%$ & $438.51 \%$ \\
Certification & Green pesticide use rate & $18.02 \%$ & $97.04 \%$ & $327.75 \%$ \\
\hline \multirow{2}{*}{ No certification\& Certification } & Green pesticide use rate & $13.98 \%$ & $59.8 \%$ & \\
\hline
\end{tabular}

As can be seen from figure 2, the use rate of green pesticides by farmers showed a decreasing trend with the increase of experiment periods. In the previous 15 periods of experiments, the use rate of green pesticides by farmers was significantly higher than the latter 15 periods. In the group of no product certification, when the agricultural subsidy ratio is only $20 \%$, the green pesticide use rate of the farmers in the latter 15 periods is $82.98 \%$ lower than the previous 15 periods. While the agriculture subsidy reached to $100 \%$, the green pesticide use rate of the farmers in the latter 15 periods is $45.83 \%$ lower than the previous 15 periods. This phenomenon is mainly caused by the fact that when farmers know that green pesticides will decrease their planting income, their production behavior will change significantly. The 15th period, the middle of the experiment, was an obvious turning point. Compared with the low agricultural subsidy ratio, the difference of farmers using green pesticides between the previous and latter 15 periods of experiments is not obvious under the higher ratio of agricultural subsidy, that is, the farmers still maintain a certain amount of green pesticides. It can also be seen from Figure 3 that the green pesticide use rate of the farmer in the experiment will change with the experiment period, showing the situation of high investment in early stage and low investment in latter. Most farmers use green pesticides in the early stage of the experiment, and only a few farmers kept low input or even zero input.

According to table 3 , when there is only subsidies for agricultural materials, the green pesticide use rate of farmers is only $9.93 \%$ with $20 \%$ agricultural subsidies. When the subsidy proportion increased to $100 \%$, the use rate of green pesticides increased to $22.3 \%$, increasing by $124.57 \%$ than the lower agricultural subsidies. When the farmers were able to obtain product certification, the green pesticide utilization rate under the low agricultural subsidy rate of $20 \%$ was $18.02 \%$. When the agricultural subsidy proportion increased to $100 \%$, the use rate of green pesticides by farmers has increased significantly to $97.04 \%$, increasing by $438.51 \%$ than the lower agricultural subsidies. Regardless of the impact of product certification, the utilization rate of green pesticides is $13.98 \%$ when the proportion of agricultural subsidies is $20 \%$, when the subsidy proportion raised to $100 \%$, 
the use rate of green pesticides increased to $59.8 \%$, increasing by $327.75 \%$ than the lower agricultural subsidies. Whether there is a policy tool for product certification, raising agricultural subsidies can keep improving the use rate of green pesticides, and the effect of improvement is more significant than certification.

Farmers only have a significant increase in the use rate of green pesticides when they have product certification and high subsidies (Group D). This phenomenon mainly caused by the fact that the existing incentives ( $\mathrm{ABC}$ group) are still insufficient to farmers, thus farmers' final income who uses green pesticide are lower. As consequence, farmers will eventually gradually reduce the use of green pesticides considering the income.
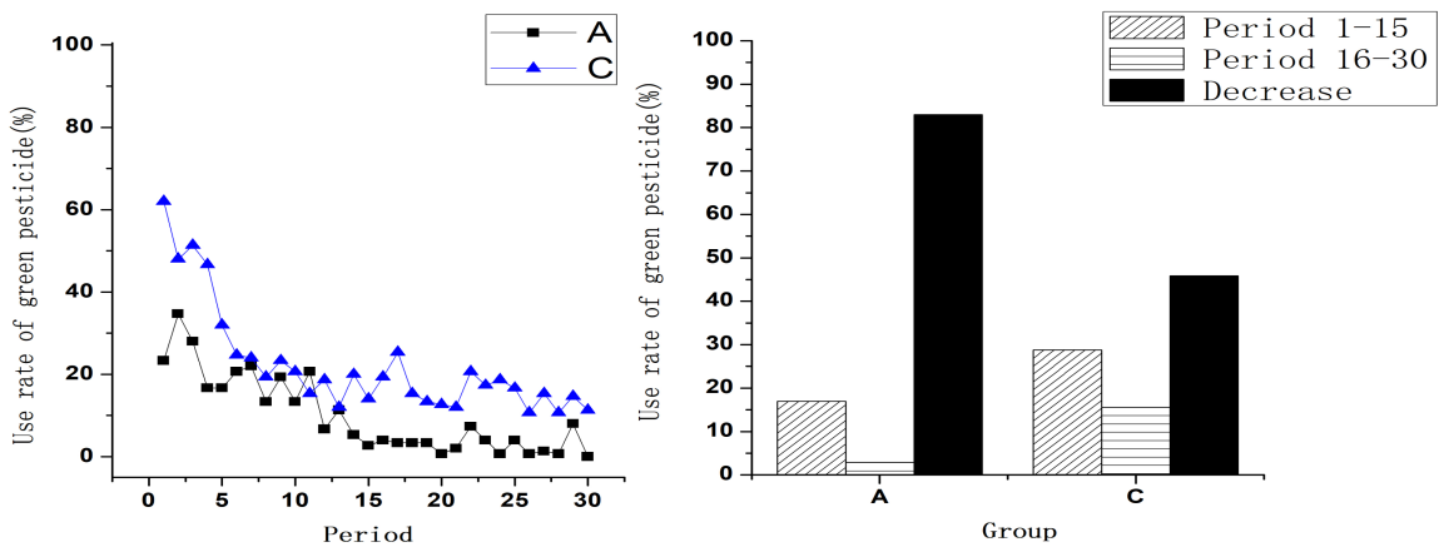

Fig 2. Comparison of green pesticide inputs by farmers in the different subsidy group
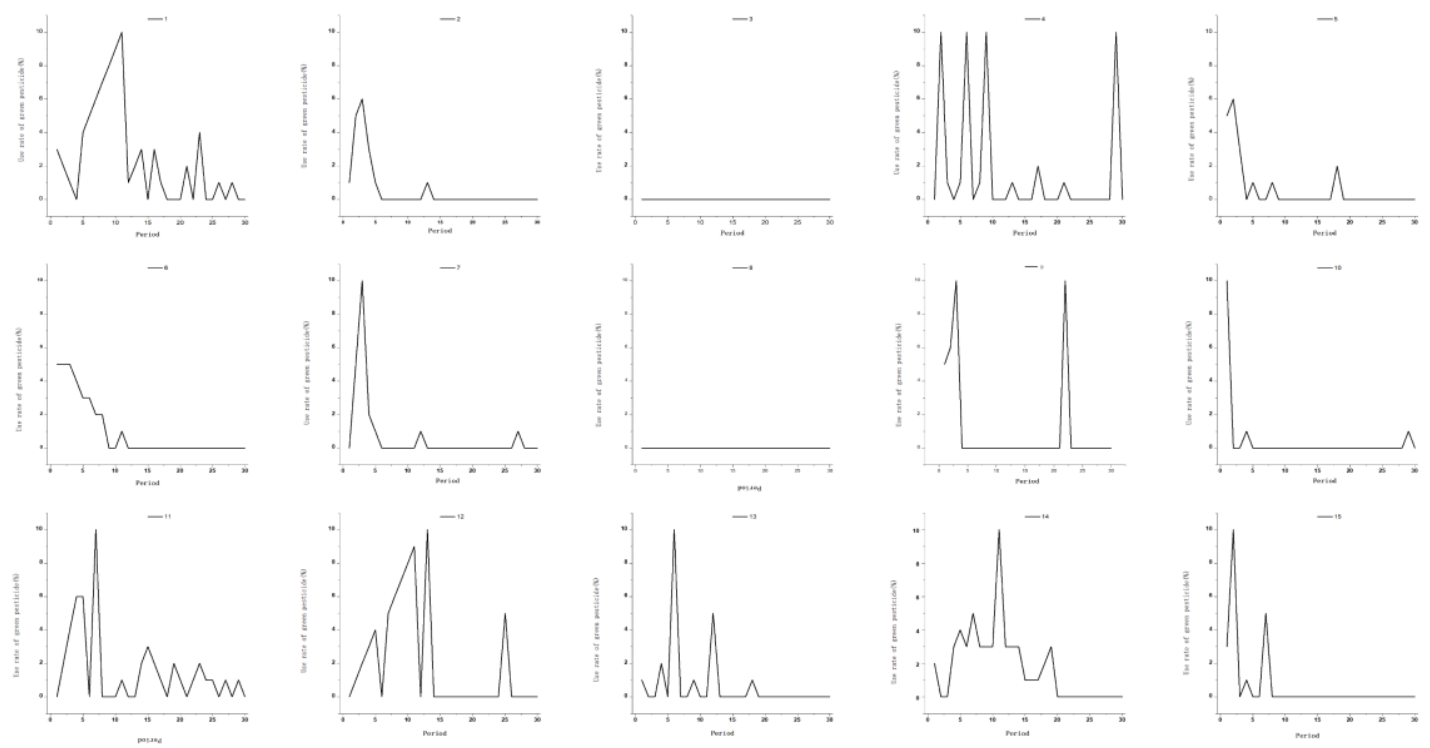

Fig 3. Specific decision of Group D

In order to analyze the influence of different agricultural subsidies on farmers' behavior accurately, this paper uses two independent sample test methods in nonparametric method --MannWhitney $U$ test methods to test the experiments results of two groups. Because the non- parametric test results are more accurate in the case where the overall characteristics of the sample are unknown, the test results showed in Table 4. 
Table 4. Mann-Whitney $U$ test for different agricultural subsidy quotas

\begin{tabular}{ccccccc}
\hline \multirow{2}{*}{ Group } & \multirow{2}{*}{ Index } & \multicolumn{2}{c}{ Low subsidy } & \multicolumn{2}{c}{ High subsidy } & \multirow{2}{*}{ P-value } \\
\cline { 3 - 6 } & & Mean & SD & Mean & SD & \\
\hline No certification & Green pesticide use rate & $9.93 \%$ & 2.26 & $22.3 \%$ & 2.83 & $\mathrm{P}<0.001$ \\
\hline Certification & Green pesticide use rate & $18.02 \%$ & 2.54 & $97.4 \%$ & 1.08 & $\mathrm{P}<0.001$ \\
\hline $\begin{array}{c}\text { No certification\& } \\
\text { Certification }\end{array}$ & Green pesticide use rate & $13.98 \%$ & 2.44 & $59.8 \%$ & 4.33 & $\mathrm{P}<0.001$ \\
\hline
\end{tabular}

From table 4, it can be concluded that in the absence of product certification as a policy tool, there is a significant difference between farmer's green pesticide use rate under the high agricultural subsidy ratio group's and the low agricultural subsidy group. When there is product certification, there is also a significant difference between farmer's green pesticide use rate between the high agricultural subsidy ratio group and the low agricultural subsidy group. Whether product certification-free or product-certified group, the high-agricultural subsidy group farmers' green pesticide use rate is still significantly higher than the low-subsidy group. In summary, when the proportion of agricultural subsidies increased from $20 \%$ to $100 \%$, the use rate of green pesticides increased by $327.75 \%$. Compared with the low proportion of agricultural subsidies, there is a significant difference in the use rate of green pesticides among farmers under the high agricultural subsidy. Therefore, hypothesis 1 confirmed.

\subsection{Analysis of the Impact of Product Certification on Farmers' Green Pesticides}

\section{Utilization Rate}

It can seen from figure 4 that when the proportion of agricultural subsidy is $20 \%$, the use rate of green pesticides by farmers is still decreasing with the increase of experimental periods. The use rate of green pesticides by farmers still stratifies throughout the experiment. The input level of green pesticides by farmers in first 15 periods was significantly higher than the last 15 periods, that is, the behavior of farmers began to change significantly in the 15th period. When the proportion of agricultural subsidies increased to $100 \%$, the use rate of green pesticides increased significantly. When the proportion of agricultural subsidies is $20 \%$, the green pesticide utilization rate of farmers without product certification is only $9.93 \%$, less than $10 \%$. When there is product certification as a policy tool, the green pesticide utilization rate of farmers raised to $18.02 \%$. Compared with no product certification group, it increased by $81.47 \%$. When the agricultural subsidy ratio is $100 \%$, the green pesticide utilization rate of the non-product certification group is $22.3 \%$, and the green pesticide utilization rate of the product certification group is $97.04 \%$, increased by $335.16 \%$. When the impact of agricultural subsidies not considered, the utilization rate of green pesticides by farmers in the product certification group reached $57.71 \%$, and the utilization rate of green pesticides in the non-product certification group was only $12.12 \%$, increased by $376.16 \%$.

Although the benefits of green pesticide production are higher than non-green pesticides in the case of high agricultural subsidies and product certification (Group D), it can be seen from figure 5 that farmers do not consistently use green pesticides. Most farmers use green pesticides showed a high input—low input—high input (stable) process, which may be explained by the fact that farmers 
have a constant attempt in the benefits of green pesticides. When farmers know the green pesticide's production income is higher by constantly testing, it will maintain a stable high input state, and the utilization rate is as high as $97.04 \%$.

Table 5. The impact of agricultural subsidies on the use rate of green pesticides

\begin{tabular}{ccccc}
\hline Group & Index & No certification & Certification & Increase \\
\hline Low subsidy & Green pesticide use rate & $9.93 \%$ & $18.02 \%$ & $81.47 \%$ \\
High subsidy & Green pesticide use rate & $22.3 \%$ & $97.04 \%$ & $335.16 \%$ \\
Low subsidy \& High subsidy & Green pesticide use rate & $12.12 \%$ & $57.71 \%$ & $376.16 \%$ \\
\hline
\end{tabular}

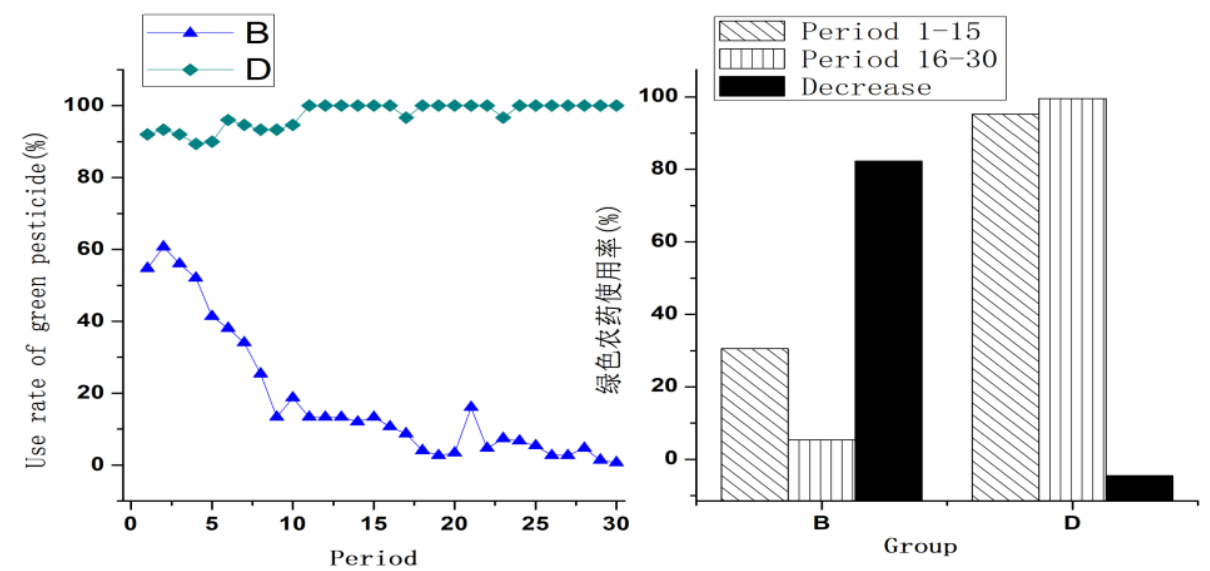

Figure 4. Comparison of green pesticide inputs by farmers in the product certification group
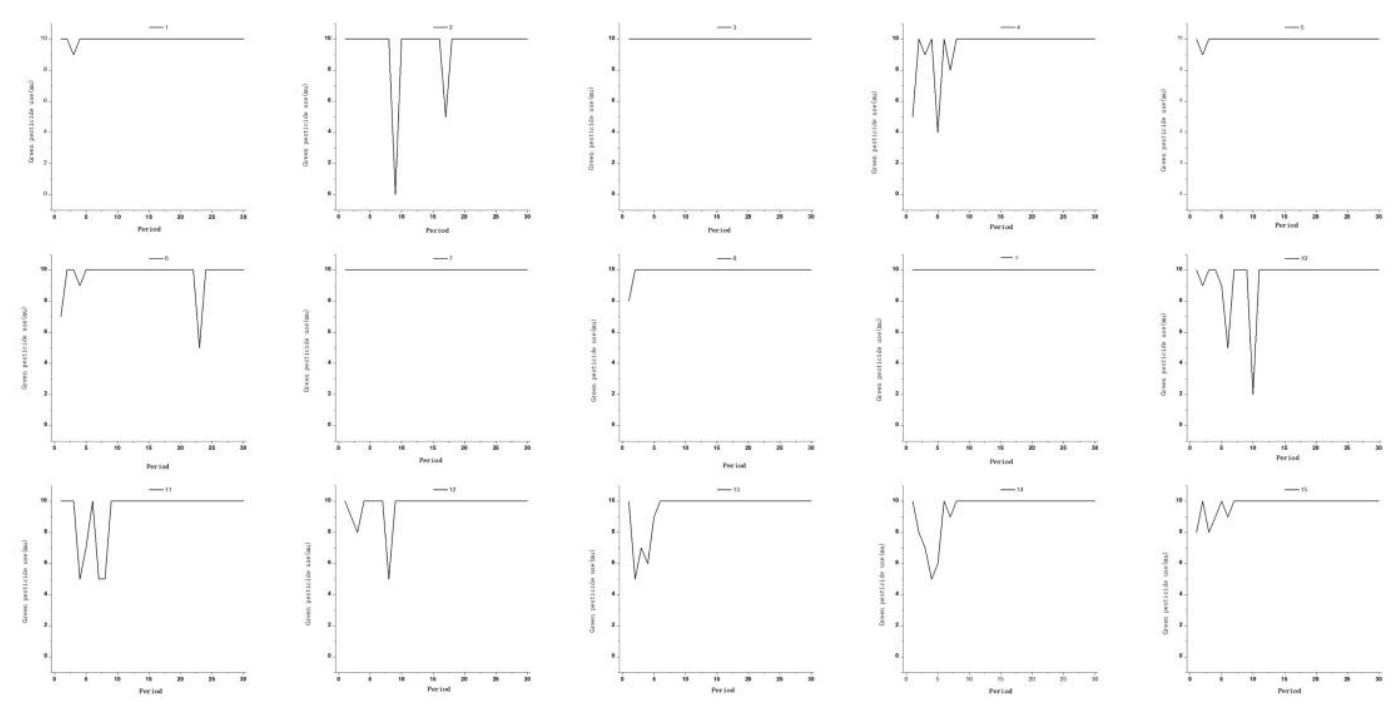

Fig 5. Specific decision of Group D

In order to accurately finding the difference of the green pesticide input levels of each group, the Kruskal-Wallis H nonparametric test using multiple independent samples is used to test and analyze the differences in the use rate of green pesticides among farmers under different product certifications. The results showed in table 6 below. 
Table 6. Product certification index Kruskal-Wallis H non-parametric test

\begin{tabular}{cllllll}
\hline \multirow{2}{*}{ Group } & \multirow{2}{*}{ Indicator } & \multicolumn{2}{c}{ No certification } & \multicolumn{2}{c}{ Certification } & \multirow{2}{*}{ P-value } \\
\cline { 3 - 6 } & & Mean & SD & Mean & SD & \\
\hline Low subsidy & Green pesticide use rate & $9.93 \%$ & 2.26 & $18.02 \%$ & 2.54 & $\mathrm{P}<0.001$ \\
\hline High subsidy & Green pesticide use rate & $22.3 \%$ & 2.54 & $97.4 \%$ & 1.08 & $\mathrm{P}<0.001$ \\
\hline Low \& High subsidy & Green pesticide use rate & $12.12 \%$ & 2.63 & $57.71 \%$ & 4.42 & $\mathrm{P}<0.001$ \\
\hline
\end{tabular}

From the test results in table 6 , it can see that regardless of the proportion of agricultural subsidies, product certification has a significant impact on the increase in the use rate of farmers' green pesticides. When the proportion of agricultural subsidies is low, product certification can increase the utilization rate of green pesticides by $81.47 \%$. The use rate of green pesticides by farmers in the product certification group is significantly different from that of no certification. When the proportion of agricultural subsidies is high, products certification can increase the use rate of green pesticides by $335.16 \%$, and there is a significant difference in the use rate of green pesticides between the two groups of farmers. Therefore, hypothesis 2 confirmed.

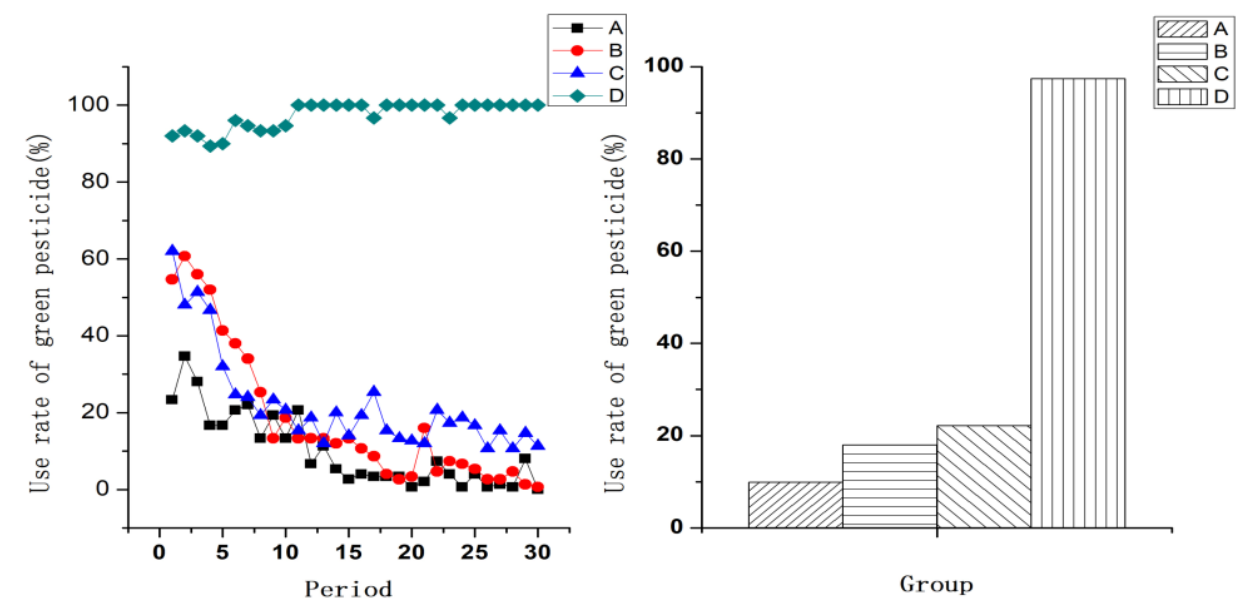

Fig 6. Comparison of four group

Overall, the average utilization rate of green pesticides in each group of farmers is: Group D (high agricultural subsidies \& product certification) $>$ Group C (high agricultural subsidies \& no certification) $>$ Group B (low agricultural subsidies \& product certification) > Group A (low agricultural subsidies \& no product certification). While the relationship between the benefits of using green pesticides is: $\mathrm{D}>\mathrm{B}>\mathrm{C}>\mathrm{A}$, the trend of green pesticide use is not exactly the same as the income trend, Group B and Group has an inconsistency. The possible explanation is that when the proportion of agricultural subsidies is high, the production behavior of farmers has a "status bias". Even if the benefits of using green pesticides are not as good as those of non-green pesticides, farmers still maintain a high green level of pesticide use rate in the later stages of the experiment.

\subsection{Analysis of the influence of the characteristics of the subjects on their behavior.}

Before starting the experiment, the participants needed to fill out a questionnaire about experimental economics, green pesticides, pest and disease prevention and control, and farmers' 
production considerations, as well as an improved risk test based on Holt and Laury's measurement questions. Descriptive analysis and empirical testing will conduct for the acquired data. In this experiment, 60 participants participated in the experiment, and four experimental bureaus were completed. Each experimental bureau was 30 periods, so 60 data on the individual characteristics of the subjects obtained. The variables selected showed in table 7 below.

Table 7. Variable description

\begin{tabular}{|c|c|c|}
\hline & Variable & Variable Meaning \\
\hline \multirow{2}{*}{$\begin{array}{l}\text { Dependent } \\
\text { variable }\end{array}$} & Input & Green pesticide input \\
\hline & Average-Input & Average value of green pesticide use per participant \\
\hline \multirow{2}{*}{$\begin{array}{l}\text { Independent } \\
\text { variable }\end{array}$} & Subsidy & Virtual variable, low subsidy group is 0 , high subsidy group is 1 \\
\hline & Certification & Virtual variable, no authentication group is 0 , authentication group is 1 \\
\hline \multirow{10}{*}{$\begin{array}{l}\text { Control } \\
\text { variable }\end{array}$} & Gender & Subject's gender \\
\hline & Age & Subject's age \\
\hline & Experimental & Subjects' understanding of experimental economics \\
\hline & Region & Subjects' understanding of the countryside \\
\hline & Diseases-pests(DP) & $\begin{array}{l}\text { Subjects' understanding of the prevention and control of pests and } \\
\text { diseases in vegetable cultivation }\end{array}$ \\
\hline & Green-pesticide(GP) & Subjects' understanding of green pesticides \\
\hline & Necessity(Necessity) & Subjects' responsibility awareness and environmental awareness \\
\hline & Willing & Willingness to use green pesticides under high cost \\
\hline & Certified-product(CP) & Subjects' understanding of certified products \\
\hline & Risk-characteristics (RC) & Risk type of subject \\
\hline
\end{tabular}

According to table 8 , the majority of the participants in this experiment were women, accounting for $76.7 \%$, aged between 18 and 27 years old with an average age of 22.08 years, and rural students accounting for $31.67 \%$. According to the results of the questionnaire, the overall understanding of experimental economics was between not well understood and understood. Some people heard but was not familiar, and only one person knew it well, accounting for $1.67 \%$. Moreover, the participants' understanding of pest control and green pesticides in vegetable production was not well, and a small number of participants were better understand. Most of the subjects were fully aware of the various hazards brought about by the production of chemical pesticides. After understanding the advantages of green pesticides, $96.67 \%$ of the participants believed that green pesticides should use. While it comes to the high cost of green pesticides, the attitude towards the selection of green pesticides changed significantly. There $43.33 \%$ participants clearly indicated that they would not use green pesticides, and $21.67 \%$ participants indicated that they would still use green pesticides. The rest said they were not sure how they would choose. Among the mentioned certification products, most of the participants were relatively unfamiliar and less aware. From the perspective of the risk appetite type, the risk-neutral subjects accounted for $43.33 \%$, and the risk-avoiding and risk-seeking subjects accounted for $18.33 \%$ and $35 \%$ respectively.

This paper constructs the model from the overall level and selects the average value of 30 periods of green pesticide input in each experimental station. The subsidy and product certification are binary discrete variables and multivariate discrete variables as explanatory variables, such as 
gender, age, understanding of experimental economics, source of birth, understanding of pests and diseases, understanding of green pesticides, necessity of using green pesticides, willingness to use green pesticides at high cost, understanding of product certification, risk type as control variables. The model constructed as follows.

AverageInput $=C+\beta_{1}$ Ssubsidy $+\beta_{2}$ Certification $+\beta_{3}$ Gender $+\beta_{4}$ Age $+\beta_{5}$ Experiment $+\beta_{6}+$ $\beta_{7} \mathrm{DP}+\beta_{8} \mathrm{GP}+\beta_{9}$ Necessity $+\beta_{10}$ Willing $+\beta_{11} \mathrm{CP}+\beta_{12} \mathrm{RP}$

Table 8. Regression result

\begin{tabular}{ccccccccc}
\hline Variable & Mean & SD & Min & Max & Skewness & Kurtosis & Coef & t-value \\
\hline Constant & - & - & - & - & - & - & -0.308 & -0.08 \\
Subsidy & - & - & - & - & - & - & $3.516^{* * * *}$ & 5.35 \\
Certification & - & - & - & - & - & - & $1.869^{* * *}$ & 4.7 \\
Gender & 0.233 & 0.427 & 0.000 & 1.000 & 1.294 & -0.339 & 0.004 & 0.01 \\
Age & 22.083 & 2.181 & 18.000 & 27.000 & 0.245 & -0.795 & -0.079 & -0.49 \\
Experiment & 1.600 & 0.924 & 0.000 & 4.000 & 0.809 & -1.394 & 0.909 & 1.28 \\
Region & 0.317 & 0.469 & 0.000 & 1.000 & 0.229 & -0.315 & 0.274 & 0.75 \\
DP & 1.383 & 0.761 & 0.000 & 3.000 & 0.410 & -0.042 & 0.261 & 0.57 \\
GP & 1.400 & 0.694 & 0.000 & 3.000 & 0.214 & -0.027 & 0.749 & 1.55 \\
Necessity & 0.967 & 0.181 & 0.000 & 1.000 & -5.334 & 27.360 & -0.931 & -0.54 \\
Willing & 0.783 & 0.783 & 0.000 & 2.000 & 0.406 & -1.247 & 0.073 & 0.16 \\
CP & 0.817 & 0.965 & 0.000 & 3.000 & 1.084 & 0.268 & 0.336 & 1.03 \\
RC & 1.167 & 0.717 & 0.000 & 2.000 & -0.259 & -0.992 & 0.002 & -0.08 \\
\hline R & & & & & 0.639 & & & \\
Sample & & & & & 60 & & & \\
\hline
\end{tabular}

From the regression results, the green pesticide purchase subsidies and product certifications are both significant at the significance level of $1 \%$, and the coefficients are positive, indicating that agricultural subsidies and product certifications have positively promoted the use of green pesticides. Moreover, the coefficient of agricultural subsidy is larger, indicating that the agricultural subsidy is more effective than the product certification for the increase of the green pesticide use rate of farmers, which is consistent with the analysis results of the previous nonparametric test.

\section{Conclusion}

This paper simulates the production decision-making situation of farmers through experimental methods and draws the following conclusions. Firstly, the main consideration factor in the decisionmaking of farmers' pesticide is still the production income. In the production process of green pesticides and non-green pesticides, when agricultural subsidies and product certification still cannot compensate for the difference in the income of green pesticides and non-green pesticides, the farmers' investment in green pesticides decreases with the increase of experimental rounds. As the time goes by, the level of green pesticide usage amount become lower. The difference between the early and late stages is distinct, and the behavior of farmers in the middle of the experiment 
changed significantly. Secondly, agricultural subsidies help to increase the use rate of green pesticides by farmers. When the proportion of agricultural subsidies raised from $20 \%$ to $100 \%$, the use rate of green pesticides increased by $438.51 \%$. Thirdly, the product certification layer has an impact on farmers' green pesticide use rate. Product certification has a significant promotion effect on the utilization of green pesticides. Compared with no product certification, the use rate of green pesticides increased by $376.16 \%$. Fourthly, the effect of the proportion of agricultural subsidies on increasing farmers' green pesticide use rate is more significant than product certification. Under a higher proportion of agricultural subsidies, farmers' behavior will produce "status bias". At the last, the results of the students' experiments not affected by the individual characteristics of the participants, so it is appropriate to select students as experimental subjects.

The primary consideration in the formulation of green pesticide promotion policies is still the farmers' income. Farmers' income is an important prerequisite for farmers' behavior change. Since the price of green pesticides is higher than the price of non-green pesticides, and the production will reduce to a certain extent, the agricultural subsidies should increase greatly to effectively improve the utilization rate of green pesticides. It is recommended that local government would provide green pesticides free of charge in areas where conditions permit. Although agricultural subsidies and product certification can improve the use rate of green pesticides, it is recommended to give priority to increasing the proportion of agricultural subsidies, then promoting product certification, since the effect of agricultural subsidies is superior to product certification, and farmers have a situation bias. In the subsequent laboratory experiments, students are suitable for experimental subjects, and the individual characteristics of the students have no significant effect on the experimental results.

\section{Reference}

[1]. Yang X S, Lin Q Y. On Factors Influencing Peasant Households' Willingness to Use Bio-rational Pesticide and Green Pesticides under the Economic Incentives__ A Study Based on the Questionnaire Survey of Peasant Households in Fujian Province.[J].Journal of Jiangxi Agriculture university(Social Sciences edition), 2011(1):50-54

[2]. Jiang L N, Zhao X. A study on paradox between farmers' purchasing willingness and purchasing behavior of green pesticides: Based on 863 farmers' survey data from five provinces in China [J]. Journal of China Agricultural University, 2017,22(5):163-173.

[3]. Wu L H, Hou B, Gao S R. Analysis of Pesticide Residue Cognition and Main Influencing Factors of Decentralized Farmers Based on Structural Equation Model[J]. China Rural Economy, 2011(3): 35-48.

[4]. Schreinemachers P, Tipraqsa P. Agricultural pesticides and land use intensification in high, middle and low income countries [J]. Food Policy, 2012, 37(6):616-626.

[5]. Ervin, David E. Soil Erosion Control on Owner- operated and Rented Cropland[J].Journal of Soil and Water Conservation,1982,37(5):285-288

[6]. Wang $\mathrm{H} \mathrm{s}, \mathrm{Xu}$ X. Micro-behavior and safety of agi-products: an analysis of rural household' production and residents' consumption [J]. Journal of Nanjing Agricultural University, 2004, 4(1): 23-28.

[7]. Goodhue R, Klonsky K, Mohapatra S, Can an Education Program Be a Substitute for a Regulatory Program That Bans Pesticides? Evidence from a Panel Selection Model[J].American Journal of Agricultural 
Economics,2010,92(4):956-971

[8]. Nowak P J. The Adoption of Agricultural Conservation Technologies: Economic and Diffusion Explanations[J].Rural Sociology, 1987,52(2):208-220

[9]. Greene, Willam H. Econometric Analysis [J].Journal of the American Association,2003,89(89):182-197

[10]. Khan M. Economic Evaluation of Health Cost of Pesticide Use: Willingness to Pay Method [J]. Pakistan Development Review, 2009, 48(4): 459-470.

[11]. Ren Z, Xue X L. Analysis on the will of the non-pollution pesticide use and its influencing factors-An empirical study based on 609 farmers [J]. Journal of Arid Land Resources and Environment, 2016, 30(7): 31 36.

[12]. Li G S, Zhang L G. Analysis of the impact of pollution-free agricultural product certification on production [J]. Journal of Jiangxi Agricultural University, 2006, 18(6): 169-172.

[13]. Wang Z G, Huang S N, He Z P. On Farmers' Cognition and Adoption of Green Pesticide in Different Agricultural Production Mode-- Based on Investigations In Haidian Beijing, Shouguang Shandong and Qingan Heilongjiang [J]. Journal of Shanxi Agricultural University Journal (Social Science Edition), 2012(5): $454-$ 459.

[14]. Zhu D, Zhang X L, Niu L Y. Vegetable Farmers' Willingness to Adopt Biopesticides [J].China Population Resources and Environment, 2014, 24(4): 64-70.

[15]. Suter J F, Vossler C A. Towards an Understanding of the Performance of Ambient Tax Mechanisms in the Field: Evidence from Upstate New York Dairy Farmers[J]. American Journal of Agricultural Economics, 2014, 96(1):92-107.

[16]. Falk A, James J. Heckman. Lab Experiments Are a Major Source of Knowledge in the Social Sciences [J]. Science, 2009, 326(5952):535-538.

[17]. Spraggon J. Exogenous targeting instruments as a solution to group moral hazards[J]. Journal of Public Economics, 1998, 84(3):427-456.

[18]. Segerson K. Uncertainty and incentives for nonpoint pollution control[J]. Journal of Environmental Economics \& Management, 2006, 15(1):87-98.

[19]. Xepapadeas A P. Environmental policy under imperfect information: Incentives and moral hazard [J]. Journal of Environmental Economics \& Management, 2014, 20(2):113-26.

[20]. Horan, R. D., Shortle, J. S. and Abler, D. G. Ambient Taxes When Polluters Have Multiple Choices [J]. Journal of Environmental Economics and Management, 1998,36 (2): 186-199

[21]. Alpízar F, Requate T, Schram A. Collective versus Random Fining: An Experimental Study on Controlling Ambient Pollution[J]. Environmental \& Resource Economics, 2004, 29(2):231-252.

[22]. Horan R D, Shortle J S, Abler D G. Ambient Taxes Under m -Dimensional Choice Sets, Heterogeneous Expectations, and Risk-Aversion[J]. Environmental \& Resource Economics, 2002, 21(2):189-202.

[23]. Suter J F, Segerson K, Vossler C A, et al. Voluntary-Threat Approaches to Reduce Ambient Water Pollution[J]. American Journal of Agricultural Economics, 2010, 92(4):1195-1213.

[24]. Cason T N, Gangadharan L. Auction Design for Voluntary Conservation Programs[J]. American Journal of Agricultural Economics, 2004, 86(5):1211-1217.

[25]. Cason T N, Gangadharan L. A Laboratory Comparison of Uniform and Discriminative Price Auctions for Reducing Non-Point Source Pollution[J]. Land Economics, 2005, 81(1):51-70.

[26]. Ferraro P J. Asymmetric information and contract design for payments for environmental services[J]. Ecological Economics, 2008, 65(4):810-821.

[27]. Glebe T W. Conservation Auctions: Should Information about Environmental Benefits Be Made Public?[J]. American Journal of Agricultural Economics, 2013, 95(3):590-605. 
[28]. Wang X M, Jin J J, Gao Y Z. Farmer coping behavior in climate change and affecting factors:method of experimental economics [J]. Journal of Beijing Normal University(Natural Science), 2016, 52(4): 501 -505

[29]. Zhao J J, Liu T J, Wei J. Does Risk Attitude Affect Apple's Safe Production Behavior_—Based on Farmers' Experimental Data in Apple Main Producing Areas [J]. Agricultural Technology \& Economy, 2017(4): 95-105

[30]. Shen Y Q, Shu B, Zhu X, et al. Impact of Forest Subsidies on Farmers' Risk Attitude in Mountain Areas: An Empirical Study Based on Investigation in Zhejiang Province [J]. Journal of Agro-forestry Economics, 2016(1):31- 38 .

[31]. Bai J D, Shen Y Q, Zhu X, et al. The Influence of Risk and Time Preference on the Farmer's Willingness to Manage Forestry Carbon Sinks [J].Issue of Forestry Economics, 2016, 36(1): 72-78.

[32]. Ying R Y, Zhu Y. The Impact of Agricultural Technical Training Methods on Farmers' Agricultural Chemical Inputs--Evidence from Experimental Economics [J]. China Rural Survey, 2015(1): 50-58 .

[33]. Chen Yusheng, Zhu Yudong, Zhang Lin. Environmentally Friendly Agricultural Materials Choice of Household Based on the Experimental Economics [J].Issue in Agriculture Economy, 2016(8): 33-40.

[34]. Liang J, Chen Y S, Yin S J. Research on Transfer Behavior of Food Safety Traceability Information based on the Experimental Economics [J]. Commercial Research, 2015, 58(6):9-17.

[35]. Zhang Y H, Ma J J, Kong X Z, et al. Analysis of Influencing Factors of Farmers' Use of Pollution-free and Green Pesticides Behavior-An Empirical Analysis of 15 Counties (Cities) in Shanxi, Shaanxi and Shandong[J]. China Rural Economy, 2004 (1): 41-49.

[36]. Daniel Houser, Luo W d, Fan L C, et al. The Rising and Challenge of Experimental Economics [J]. Journal of Zhejiang University (Humanities and Social Sciences), 2012, 42(4): 37-46.

[37]. Fischbacher U. z-Tree: Zurich toolbox for ready-made economic experiments.[J]. Experimental Economics, 2007, 10(2): 171-178 